\title{
PARP16 is a tail-anchored endoplasmic reticulum protein required for the PERK- and IRE1 $\alpha$-mediated unfolded protein response
}

\author{
Miri Jwa \& Paul Chang
}

Nat. Cell Biol. 14, 1223-1230 (2012); published online 28th October 2012; corrected online 15th November 2012

While this manuscript was under consideration, an article by Di Paola et al. reported an ER localization for PARP16. In the version of this Letter initially published online and in print, the reference (PLOS ONE 7, e37352; 2012) was inadvertently omitted from the reference list. On page 8 , the following text has replaced the previous text:

We show that the ER-associated tail-anchored protein PARP16 selectively ADP-ribosylates PERK and IRE1a during the UPR, and that such modification is required for activation of PERK and IRE1 $\alpha$ at least in part by increasing their kinase and endonuclease activities. While this manuscript was under revision, Di Paola et al. independently showed that PARP16 is ER-localised, and a tail-anchored protein ${ }^{22}$. Interestingly, Saccharomyces cerevisiae lacks PARP proteins and has only one ER stress sensor, Ire1.

The omitted reference has now been added to the reference list:

22. Di Paola, S., Micaroni, M., Di Tullio, G., Buccione, R. \& Di Girolamo, M. PARP16/ARTD15 is a novel endoplasmic-reticulum-associated mono-ADP-ribosyltransferase that interacts with, and modifies karyopherin- $\beta 1$. PLoS ONE 7, e37352 (2012).

References 22-27 have been changed to $23-28$, respectively.

\section{MCUR1 is an essential component of mitochondrial $\mathrm{Ca}^{2+}$ uptake that regulates cellular metabolism}

\author{
Karthik Mallilankaraman, César Cárdenas, Patrick J. Doonan, Harish C. Chandramoorthy, Krishna M. Irrinki, \\ Tünde Golenár, György Csordás, Priyanka Madireddi, Jun Yang, Marioly Müller, Russell Miller, Jill E. Kolesar, \\ Jordi Molgó, Brett Kaufman, György Hajnóczky, J. Kevin Foskett and Muniswamy Madesh
}

Nat. Cell Biol. 14, 1336-1343 (2012); published online 25th November 2012; corrected online 30 th November 2012

In the version of this Letter that was originally published, the affiliation of Jordi Molgó was erroneous. The correct affiliation is: CNRS, Institut de Neurobiologie Alfred Fessard FRC2118, Laboratoire de Neurobiologie et Développement, UPR 3294, 91198 Gif-sur-Yvette cedex, France.

This has now been corrected online. 